Pride of place must go to the article by Feng-hsiung Hsu, Thomas Anantharaman, Murray Campbell and Andreas Nowatzyk, having been given the signal honour of publication as the premier contribution in the Scientific American for October 1990. Next to this, the current issue of this Journal features a long essay about PIONEER, certainly reflecting the cast of mind of the Pioneer-in-Chief, Dr. M.M. Botvinnik. This is all the more remarkable since for the last 20 years Dr. Botvinnik had acquired a great reputation for coyness about his efforts in computer chess.

This flurry of openness allows us to make a simple observation about a common trend which we believe to be of profound significance. Botvinnik and his team were in search of a chess program with a human face, or even more ambitiously, with a Grandmaster's mind. Hsu and his team have been accused of applying mere brute force, which to chess-players has an inhuman taint to it and tends to be looked down upon. Yet the Scientific American article very clearly shows that brute force certainly no longer is all that brutish, if it ever was. Metaphorically speaking Deep Thought has been nurtured on a fare of Grandmaster games which served to tune its evaluation function. This function, involving no less than about 120 criteria can no longer be sneered away as being greedily acquisitive or simple-minded. We believe there is convergence, Botvinnik starting from the human angle and Hsu and his team from the machine's point of view.

Yet the goals aimed at are remarkably close. True, differences remain: there is a vast gap in speed and one might catch Botvinnik in the act of felling entire trees, whereas Hsu prudently prunes them. Also, of course, Deep Thought has the advantage of having the experience of many games and the prospect of many more to come, whereas PIONEER has no experience of playing and is to some extent backward-looking, in many ways mimicking some of the Pioneer-in-Chief's past triumphs.

These quibbles apart, the fact of convergence remains. Force there may be, but it will no longer do to write off force as being inherently brutish, nor will it be acceptable for deeply analytical programs to be dismissed as merely theoretical. The prime contestants seem to converge in uniting on the idea that force should be applied masterfully.

All manner of fascinating sidelights emerge from this glasnost. Hsu and two of his teammates have recently joined IBM, so the reader is free to speculate where the fastest, deepest and bluest chess program is going to come from in the next few years. It will also interest our readers in the small world we live in that Hsu's Ph.D. thesis has been singled out for the Mephisto "Best Publication" Award, surely a long way to come from what started out as an academically unsupported exercise. The newest and the old are nicely commingled in our world too: bridging thirteen years, an ocean and a language gap, Ken Thompson confirmed the validity of the granddaddy of all databases, Arlazarov and Futer's analysis of the KRPKR endgame, which he praises as "a superhuman [piece of] work".

Glasnost, convergence, confirmation - what better can one wish for in this festive season?

Christmas 1990

Bob Herschberg Jaap van den Herik

\title{
Newborn Receives ACM's Outstanding Contribution Award
}

During the ACM Conference in New York, November 1990, Professor Monroe Newborn, our former President, has received the Outstanding Contribution Award in recognition of his role in the annual ACM Computer-Chess Championship. In all 21 tournaments, he has served as an ACM organizer, many times being a competitor (OSTRICH) and always encouraging talented people to enter the toumament. The Editorial Board congratulates Professor Newborn with this Award and feels assured that our readership concurs in the congratulations. 